\title{
The TNFA -857C/T Polymorphism: Association with Rheumatoid Arthritis and Anti-CCP Levels in a Mexican Population
}

\author{
Juan Manuel Agraz-Cibrián, ${ }^{1}$ Gabriela Nohemí Espinoza-De León, ${ }^{1}$ \\ Ma. de Jesús Durán-Avelar, ${ }^{1}$ Norberto Vibanco-Pérez, ${ }^{1}$ Liliana Ortiz-Martínez, ${ }^{2}$ \\ Alejandro Vázquez-Reyes, ${ }^{1}$ Jorge Gutiérrez-Franco, ${ }^{1}$ Miriam Fabiola Ayón-Pérez, \\ and José Francisco Zambrano-Zaragoza (iD) ${ }^{1}$ \\ ${ }^{1}$ Unidad Académica de Ciencias Químico Biológicas y Farmacéuticas, Universidad Autónoma de Nayarit, Tepic, Nayarit, Mexico \\ ${ }^{2}$ Clínica de Reumatología, Servicio de Medicina Interna, Instituto Mexicano del Seguro Social HGZ No. 1, Tepic, Nayarit, Mexico
}

Correspondence should be addressed to José Francisco Zambrano-Zaragoza; jzambran44@gmail.com

Received 7 May 2019; Accepted 5 September 2019; Published 9 October 2019

Academic Editor: Francesca Santilli

Copyright (c) 2019 Juan Manuel Agraz-Cibrián et al. This is an open access article distributed under the Creative Commons Attribution License, which permits unrestricted use, distribution, and reproduction in any medium, provided the original work is properly cited.

\begin{abstract}
Rheumatoid arthritis (RA) is a chronic inflammatory disease whose association with SNPs has led to the identification of biomarkers in different populations. To determine the association of the $-857 \mathrm{C} / \mathrm{T}$ SNP of the TNFA gene with RA and clinical parameters, $233 \mathrm{RA}$ patients and 237 healthy controls were included in this study. The -857C/T polymorphism was determined using the TaqMan ${ }^{\circledR}$ system and clinical features were also determined. We found that the -857C/T SNP was in Hardy-Weinberg equilibrium. Our results showed no association of the $-857 \mathrm{C} / \mathrm{T}$ SNP with RA; however, RA patients carrying the TT genotype showed lower anti-CCP levels than other groups. Therefore, the TT genotype could be a risk factor for developing anti-CCPnegative RA. Our results suggest that the T allele of the TNFA -857C/T SNP exerts an influence on anti-CCP levels and could be a candidate marker for anti-CCP-negative RA.
\end{abstract}

\section{Introduction}

Rheumatoid arthritis (RA) is a chronic inflammatory disease that affects joints, with a prevalence of approximately $1 \%$ in the worldwide population, [1] but with an overall prevalence in Mexico estimated at 1.6\% [2]. Women are affected more often than men, in a proportion of $3: 1$ [1]. RA is characterized by the production of two known antibodies, called rheumatoid factor (RF) and anticyclic citrullinated peptide antibodies (CCP) [3]. It has been reported that the anti-CCP antibodies are present in about two-thirds of RA patients [4]. Therefore, RA can be considered to contain two separate subsets: antiCCP-positive and anti-CCP-negative, each with distinct genetic and environmental risk factors [5].

RA is an autoimmune disease that involves both environmental and genetic factors. The impact of genetic factors compared to environmental ones is supported by the $15-30 \%$ concordance rates of RA in monozygotic twins. Moreover, it has been shown that up to $60 \%$ of disease susceptibility is due to genetic factors [6], including the polymorphisms in genes that encode proinflammatory cytokines, which can play an important role by amplifying the inflammatory events that this disease triggers [7].

Tumor necrosis factor alpha (TNF $\alpha$ ) is a potent pleiotropic proinflammatory cytokine produced mainly by macrophages, though other cells, such as T, B, and NK cells can produce it as well [8]. Among the functions of $\mathrm{TNF} \alpha$, the secretion of other cytokines increases the expression of adhesion molecules in the endothelium and promotes neutrophil activation and migration. Costimulatory effects on T-cell activation and antibody production by B-lymphocytes have been implicated in RA pathogenesis [7]. In addition, RA patients with elevated levels of TFN $\alpha$ in sera and synovial fluid show greater articular damage [9]. 
The TNFA gene is located on the short arm of chromosome 6 at locus $6 \mathrm{p} 21.3$ in the $\mathrm{MCH}$ class III region [7]. Among the SNPs described in the promoter region of TNFA, the $-857 \mathrm{C} / \mathrm{T}$ SNP affects the transcription of the TNFA gene.

The $-857 \mathrm{~T}$ allele variant of the TNFA promoter contains a transcription factor OCT1 binding site (ATGAAGAC) from position -858 to position -851 . OCT1 binds to the sequence only with the $-857 \mathrm{~T}$ allele, but not with the $-857 \mathrm{C}$ allele, and then inhibits TNFA promoter and expression activity $[10,11]$.

In the present study, we determined the association of the TNFA -857C/T SNP with RA and the effect of the genotypes of this SNP on anti-CCP levels, DAS28, and sHAQ-DI in a group of RA patients from western Mexico.

\section{Materials and Methods}

2.1. Subjects. A total of 233 consecutive, unrelated RA patients, regardless of disease duration, participated in this study. All were diagnosed according to the ACR/EULAR 2010 criteria [12] at the IMSS General Hospital No. 1 in Tepic Nayarit, Mexico. The DAS28 (Disease Activity Scores using 28-joint counts) [13] and sHAQ-DI (Spanish version of the Health Assessment Questionnaire Disability Index) scores [14] were determined by an experienced rheumatologist. A total of 237 clinically healthy subjects were included as a control group. All participants were Mexican residents from the state of Nayarit who gave their informed consent prior to inclusion in the study, according to the 1964 Declaration of Helsinki and its later amendments [15]. The study was approved by the local ethics committee at the Instituto Mexicano del Seguro Social, Tepic, Nayarit (protocol number 1802, approved on 25 March 2013).

2.2. Genotyping the TNFA -857C/T SNP and Anticyclic Citrullinated Peptides Antibody (Anti-CCP) Levels. To genotype the TNFA -857C/T SNP, we used the predesigned SNP genotyping assay (part number: C_11918223_10, Foster City, CA, USA) provided by Applied Biosystems. To determine the anticyclic citrullinated peptides antibody (anti-CCP) levels by enzyme-linked immunosorbent assay (ELISA) (DRG, EIA-5653), we followed the methods outlined in DuránAvelar et al. [16].

2.3. Statistical Analyses. All statistical analyses were done following the methods in Durán-Avelar et al. [16].

\section{Results}

As Table 1 shows, $91.85 \%$ of the RA patients were female and $73.4 \%$ of them were positive to anti-CCP. No significant differences in age or the female/male ratio were found between RA patients and controls.

Our results show that the TNFA -857C/T polymorphism was in Hardy-Weinberg equilibrium in both patients and controls ( $p=0.31$ and 0.81 , respectively). However, no significant association of the $-857 \mathrm{C} / \mathrm{T}$ polymorphism has been found between RA patients (regardless of their anti-CCP status) and controls in any of the genetic models tested (Table 2).
TABLE 1: Sociodemographic and clinical characteristics of RA patients and controls.

\begin{tabular}{|c|c|c|c|}
\hline & \multicolumn{2}{|c|}{ RA patients } & \multirow[b]{2}{*}{ Controls } \\
\hline & $\begin{array}{l}\text { Anti-CCP- } \\
\text { positive }\end{array}$ & $\begin{array}{l}\text { Anti-CCP- } \\
\text { negative }\end{array}$ & \\
\hline$n$ & 171 & 62 & 237 \\
\hline Age & $53.04 \pm 14.6$ & $51.9 \pm 12.02$ & $49.9 \pm 12.7$ \\
\hline Female/male & $158 / 13$ & $56 / 6$ & $218 / 19$ \\
\hline $\mathrm{DAS} 28^{\mathrm{a}}$ & $4.33 \pm 1.4$ & $4.24 \pm 1.4$ & - \\
\hline Anti-CCP $(\mathrm{U} / \mathrm{mL})^{\mathrm{a}}$ & $334.9 \pm 665.25$ & $4.4 \pm 2.09$ & - \\
\hline sHAQ-DI ${ }^{\mathrm{b}}$ & $1.0(0.0,2.5)$ & $1.0(0.0,2.0)$ & - \\
\hline Treatment & & & - \\
\hline Biologics $(n)$ & 32 & 4 & - \\
\hline Etanercept & 22 & 3 & - \\
\hline Adalimumab & 9 & 0 & - \\
\hline Tocilizumab & 1 & 1 & - \\
\hline Methotrexate $(n)$ & 171 & 55 & - \\
\hline Corticosteroids $(n)$ & 155 & 50 & - \\
\hline
\end{tabular}

RA: rheumatoid arthritis; anti-CCP: anticyclic citrullinated peptide antibodies; DAS28: Disease Activity Scores using 28-joint counts; sHAQ-DI: Spanish version of the Health Assessment Questionnaire Disability Index. ${ }^{\mathrm{a}}$ Mean \pm SD; ${ }^{\mathrm{b}}$ median (min, max).

To determine whether the $-857 \mathrm{C} / \mathrm{T}$ SNP has an effect on anti-CCP levels, the RA patients were divided into two groups-anti-CCP-positive or anti-CCP-negative-and the association with the $-857 \mathrm{C} / \mathrm{T}$ SNP was ascertained. The $\mathrm{T}$ allele could be a risk factor for developing anti-CCPnegative RA (codominant, recessive, and addictive models, $\mathrm{OR}=3.8456,3.5204$, and 1.6923; 95\% CI: 1.3028-11.3512, 1.2087-10.2535, and 1.0573-2.7086, respectively), although the large confidence intervals could be due to the small size of the TT genotype (Table 3 ). Hence, this finding requires further analysis with a larger sample of anti-CCP-negative RA patients.

Another finding was that the RA patients who carried the TT genotype showed lower levels of anti-CCP (Figure 1) than those with the CT $(p=0.0152)$ or CC genotypes $(p=0.0024)$. However, the DAS28 and sHAQ-DI scores showed no statistical differences between RA patients grouped according to their genotypes (ANOVA test, $p=0.813$, and KruskalWallis test, $p=0.746$, respectively).

\section{Discussion}

The present study analyzed the association of the TNFA $-857 \mathrm{C} / \mathrm{T}$ SNP with RA. It determined that the TNFA -857C/T SNP is not associated with the risk of developing RA. Few studies of the association of this SNP with RA have been published, but our data agree with those reported for a Pakistani population [17], though not with those from a Chinese Han sample. It is important to note that the allelic frequencies in the study of the Chinese Han population were not in the Hardy-Weinberg equilibrium [18]. We further found that RA patients carrying the TT genotype showed lower anti-CCP levels than those with the CT or 
TABLE 2: Association of the TNFA -857C/T polymorphism in RA patients compared to controls.

\begin{tabular}{|c|c|c|c|c|c|c|}
\hline \multirow{2}{*}{ Genetic model } & \multirow{2}{*}{ Genotype } & \multicolumn{2}{|c|}{ Frequencies } & \multirow{2}{*}{ OR } & \multirow{2}{*}{$95 \% \mathrm{CI}$} & \multirow{2}{*}{$p$} \\
\hline & & $\mathrm{RA}(n=233)$ & Controls $(n=237)$ & & & \\
\hline \multirow{3}{*}{ Co } & CC & 166 & 166 & 1.0000 & - & - \\
\hline & CT & 58 & 64 & 0.9063 & $(0.5980-1.3735)$ & 0.642 \\
\hline & TT & 9 & 7 & 1.2857 & $(0.4683-3.5302$ & 0.625 \\
\hline \multirow{2}{*}{ Do } & $\mathrm{CC}$ & 147 & 166 & \multirow{2}{*}{0.9437} & \multirow{2}{*}{$(0.6344-1.4038)$} & \multirow{2}{*}{0.884} \\
\hline & $\mathrm{CT}+\mathrm{TT}$ & 61 & 71 & & & \\
\hline \multirow{2}{*}{$\operatorname{Re}$} & $\mathrm{CC}+\mathrm{CT}$ & 224 & 230 & \multirow{2}{*}{1.3202} & \multirow{2}{*}{$(0.4834-3.6056)$} & \multirow{2}{*}{0.587} \\
\hline & TT & 9 & 7 & & & \\
\hline \multirow{2}{*}{ Additive } & $\mathrm{C}$ & 390 & 396 & \multirow{2}{*}{1.3055} & \multirow{2}{*}{$(0.814-3.5402)$} & \multirow{2}{*}{0.952} \\
\hline & $\mathbf{T}$ & 76 & 78 & & & \\
\hline
\end{tabular}

RA: rheumatoid arthritis; CI: confidence interval; OR: odds ratio; Co: codominant; Do: dominant; Re: recessive.

TABLE 3: Association of the TNFA -857C/T polymorphism in RA patients with anti-CCP-negative status to controls.

\begin{tabular}{|c|c|c|c|c|c|c|}
\hline \multirow{2}{*}{ Genetic model } & \multirow{2}{*}{ Genotype } & \multicolumn{2}{|c|}{ Frequencies } & \multirow{2}{*}{ OR } & \multirow{2}{*}{$95 \% \mathrm{CI}$} & \multirow{2}{*}{$p$} \\
\hline & & $\mathrm{RA}(n=62)$ & Controls $(n=237)$ & & & \\
\hline \multirow{3}{*}{ Co } & $\mathrm{CC}$ & 37 & 166 & 1.0000 & - & - \\
\hline & CT & 19 & 64 & 1.3319 & $0.7138-2.855$ & 0.367 \\
\hline & TT & 6 & 7 & 3.8456 & $1.3028-11.3512$ & 0.014 \\
\hline \multirow{2}{*}{ Do } & CC & 37 & 166 & \multirow{2}{*}{1.5797} & \multirow{2}{*}{$0.873-2.8126$} & \multirow{2}{*}{0.120} \\
\hline & $\mathrm{CT}+\mathrm{TT}$ & 25 & 71 & & & \\
\hline \multirow{2}{*}{$\operatorname{Re}$} & $\mathrm{CC}+\mathrm{CT}$ & 56 & 230 & \multirow{2}{*}{3.5204} & \multirow{2}{*}{$1.2087-10.2535$} & \multirow{2}{*}{0.0121} \\
\hline & TT & 6 & 7 & & & \\
\hline \multirow{2}{*}{ Additive } & $\mathrm{C}$ & 93 & 396 & \multirow{2}{*}{1.6923} & \multirow{2}{*}{$1.0573-2.7086$} & \multirow{2}{*}{0.020} \\
\hline & $\mathbf{T}$ & 31 & 78 & & & \\
\hline
\end{tabular}

RA: rheumatoid arthritis; CI: confidence interval; OR: odds ratio; Co: codominant; Do: dominant; Re: recessive.

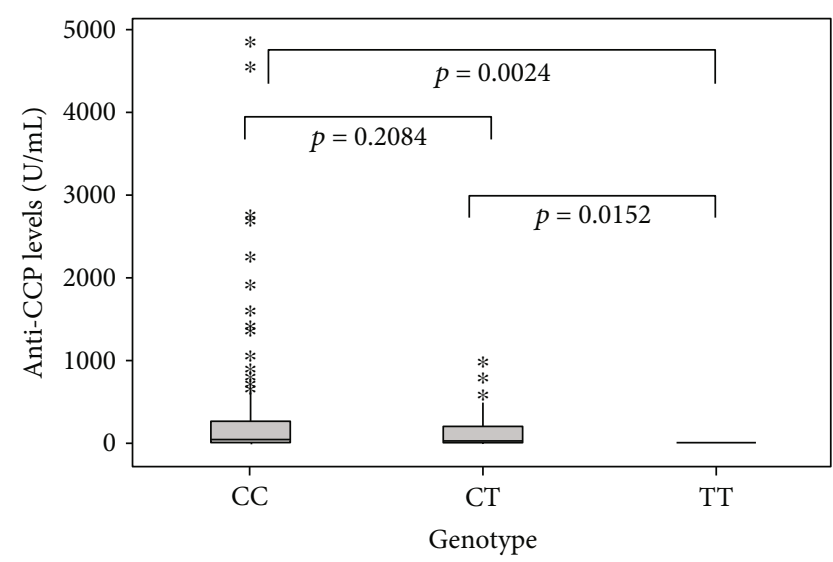

FIGURE 1: Anti-CCP levels in RA patients grouped according to their genotype, -857-C/T. Comparisons were performed using the MannWhitney $U$ test.

CC genotypes (Figure 1). As mentioned above, the T allele of this SNP affects TNFA expression, and it has been reported that blocking TNF $\alpha$ decreases anti-CCP levels [19], suggesting that TNF $\alpha$ is necessary for anti-CCP production.
Moreover, B cells play a pivotal role in RA pathogenesis [20]. It has been reported that blocking TNF $\alpha$ does not affect the expression of CD154 on B cells, so the promotion of $\mathrm{B}$ and $\mathrm{T}$ cell proliferation, antibody formation, and immunoglobulin switching are not affected [19].

This is the first study to report the association of this SNP with anti-CCP levels, suggesting the role that this SNP plays in relation to clinical features of RA.

RA can also be understood as containing two separate subsets-anti-CCP-positive and anti-CCP-negative-each with distinct genetic and environmental risk factors [5]. The $\mathrm{T}$ allele of the $-857 \mathrm{C} / \mathrm{T}$ SNP could be a risk factor for developing the anti-CCP-negative RA (Table 3), but not the anti-CCP-positive RA (data not shown), though this affirmation requires further analysis with a larger sample of antiCCP-negative RA to confirm the role of this SNP in this sub-type of RA. This fact could be explained by the finding that the putative lower production of TNF $\alpha$ [10] could provoke less inflammation, making early diagnoses difficult, since cases must show greater joint inflammation than antiCCP-positive patients to be classified as RA, according to the 2010 criteria. The pathogenesis of this RA subset is less well understood than the anti-CCP-positive RA subset [5], though there are reports that anti-CCP-positive RA patients 
experience longer disease duration [21], higher acute-phase reactants, short-term radiographic progression [22], and a reduced response to anti-TNF treatment [23]. These features are likely due to lower TNF $\alpha$ production, because studies have found that $\mathrm{TNF} \alpha$ is required for anti-CCP production [19] and that anti-CCP promotes local inflammation; therefore, they are related to the severity of RA. These data suggest that the behavior of the disease could differ in antiCCP-positive vs. anti-CCP-negative patients. These results could contribute to proposing an additional marker for anti-CCP-negative RA.

Our results suggest that the $\mathrm{T}$ allele of the TNFA $-857 \mathrm{C} / \mathrm{T}$ SNP influences anti-CCP levels and could be a candidate marker for analysis as a risk factor for anti-CCP-negative RA.

\section{Data Availability}

The genotype, anti-CCP levels, DAS28, and HAQ values used to support the findings of this study are available from the corresponding author upon request.

\section{Conflicts of Interest}

The authors declare that they have no conflict of interest.

\section{Acknowledgments}

This work was supported by the Institutional Improvement of Educational Quality Program (PROFOCIE 2014-18MSU0019M-04-01 and 2016-18MSU0019M-04).

\section{References}

[1] J. Alam, I. Jantan, and S. N. A. Bukhari, "Rheumatoid arthritis: recent advances on its etiology, role of cytokines and pharmacotherapy," Biomedicine \& Pharmacotherapy, vol. 92, pp. 615-633, 2017.

[2] R. Burgos-Vargas, L. J. Catoggio, C. Galarza-Maldonado, K. Ostojich, and M. H. Cardiel, "Current therapies in rheumatoid arthritis: a Latin American perspective," Reumatología Clínica, vol. 9, no. 2, pp. 106-112, 2013.

[3] M.-C. Boissier, L. Semerano, S. Challal, N. SaidenbergKermanac'h, and G. Falgarone, "Rheumatoid arthritis: from autoimmunity to synovitis and joint destruction," Journal of Autoimmunity, vol. 39, no. 3, pp. 222-228, 2012.

[4] L. I. Sakkas, D. P. Bogdanos, C. Katsiari, and C. D. Platsoucas, "Anti-citrullinated peptides as autoantigens in rheumatoid arthritis-relevance to treatment," Autoimmunity Reviews, vol. 13, no. 11, pp. 1114-1120, 2014.

[5] D. M. Boeters, C. Gaujoux-Viala, A. Constantin, and A. H. M. van der Helm-van Mil, "The 2010 ACR/EULAR criteria are not sufficiently accurate in the early identification of autoantibody-negative rheumatoid arthritis: results from the Leiden-EAC and ESPOIR cohorts," Seminars in Arthritis and Rheumatism, vol. 47, no. 2, pp. 170-174, 2017.

[6] G. Orozco, B. Z. Alizadeh, A. M. Delgado-Vega et al., "Association of STAT4 with rheumatoid arthritis: a replication study in three European populations," Arthritis and Rheumatism, vol. 58, no. 7, pp. 1974-1980, 2008.

[7] A. L. Boechat, N. O. Boechat, M. M. Ogusku et al., "The influence of a TNF gene polymorphism on the severity of rheumatoid arthritis in the Brazilian Amazon," Cytokine, vol. 61, no. 2, pp. 406-412, 2013.

[8] S. M. J. Harney, J. L. Newton, and B. P. Wordsworth, "Molecular genetics of rheumatoid arthritis," Current Opinion in Pharmacology, vol. 3, no. 3, pp. 280-285, 2003.

[9] T. Saxne, M. A. Palladino, D. Heinegãrd, N. Talal, and F. A. Wollheim, "Detection of tumor necrosis factor $\alpha$ but not tumor necrosis factor $\beta$ in rheumatoid arthritis synovial fluid and serum," Arthritis and Rheumatism, vol. 31, no. 8, pp. 10411045, 1988.

[10] C. P. Kang, K. W. Lee, D. H. Yoo, C. Kang, and S. C. Bae, "The influence of a polymorphism at position -857 of the tumour necrosis factor alpha gene on clinical response to etanercept therapy in rheumatoid arthritis," Rheumatology, vol. 44, no. 4, pp. 547-552, 2005.

[11] J. G. de Oliveira and A. E. Silva, "Polymorphisms of the TLR2 and TLR4 genes are associated with risk of gastric cancer in a Brazilian population," World Journal of Gastroenterology, vol. 18, no. 11, pp. 1235-1242, 2012.

[12] D. Aletaha, T. Neogi, A. J. Silman et al., "2010 Rheumatoid arthritis classification criteria: an American College of Rheumatology/European League Against Rheumatism collaborative initiative," Annals of the Rheumatic Diseases, vol. 69, no. 9, pp. 1580-1588, 2010.

[13] M. L. L. Prevoo, M. A. van'T Hof, H. H. Kuper, M. A. van Leeuwen, L. B. A. van de Putte, and P. L. C. M. van Riel, "Modified disease activity scores that include twenty-eightjoint counts development and validation in a prospective longitudinal study of patients with rheumatoid arthritis," Arthritis and Rheumatism, vol. 38, no. 1, pp. 44-48, 1995.

[14] M. H. Cardiel, M. Abello-Banfi, R. Ruiz-Mercado, and D. Alarcon-Segovia, "How to measure health status in rheumatoid arthritis in non-English speaking patients: validation of a Spanish version of the health assessment questionnaire disability index (Spanish HAQ-DI)," Clinical and Experimental Rheumatology, vol. 11, no. 2, pp. 117-121, 1993.

[15] Association WM, "World Medical Association Declaration of Helsinki: ethical principles for medical research involving human subjects," Journal of the American Medical Association, vol. 310, no. 20, p. 2191, 2013.

[16] M. de Jesús Durán-Avelar, N. Vibanco-Pérez, R. R. HernándezPacheco, A. del Carmen Castro-Zambrano, L. Ortiz-Martínez, and J. F. Zambrano-Zaragoza, "STAT4 rs7574865 G/T polymorphism is associated with rheumatoid arthritis and disease activity, but not with anti-CCP antibody levels in a Mexican population," Clinical Rheumatology, vol. 35, no. 12, pp. 2909-2914, 2016.

[17] T. Sadaf, P. John, A. Bhatti et al., "Lack of tumor necrosis factor alpha gene polymorphism -857c/t (rs1799724) association in Pakistani rheumatoid arthritis patients," International Journal of Rheumatic Diseases, vol. 19, no. 11, pp. 1119-1125, 2016.

[18] C.-g. You, X.-j. Li, Y.-m. Li et al., "Association analysis of single nucleotide polymorphisms of proinflammatory cytokine and their receptors genes with rheumatoid arthritis in northwest Chinese Han population," Cytokine, vol. 61, no. 1, pp. 133-138, 2013.

[19] C.-H. Tung, M. C. Lu, N. S. Lai, and S. F. Wu, "Tumor necrosis factor- $\alpha$ blockade treatment decreased CD154 (CD40-ligand) expression in rheumatoid arthritis," PLoS One, vol. 12, no. 8, p. e0183726, 2017.

[20] A. Gardette, S. Ottaviani, F. Tubach et al., "High anti-CCP antibody titres predict good response to rituximab in patients 
with active rheumatoid arthritis," Joint Bone Spine, vol. 81, no. 5, pp. 416-420, 2014.

[21] M. B. Hamad, S. Marzouk, N. Kaddour et al., "Anticyclic citrullinated peptide antibody and rheumatoid factor in south Tunisian patients with rheumatoid arthritis: association with disease activity and severity," Journal of Clinical Laboratory Analysis, vol. 28, no. 1, pp. 21-26, 2014.

[22] G. Mouterde, C. Lukas, P. Goupille et al., "Association of anticyclic citrullinated peptide antibodies and/or rheumatoid factor status and clinical presentation in early arthritis: results from the ESPOIR cohort," The Journal of Rheumatology, vol. 41, no. 8, pp. 1614-1622, 2014.

[23] C. Potter, K. L. Hyrich, A. Tracey et al., "Association of rheumatoid factor and anti-cyclic citrullinated peptide positivity, but not carriage of shared epitope or PTPN22 susceptibility variants, with anti-tumour necrosis factor response in rheumatoid arthritis," Annals of the Rheumatic Diseases, vol. 68, no. 1, pp. 69-74, 2009. 


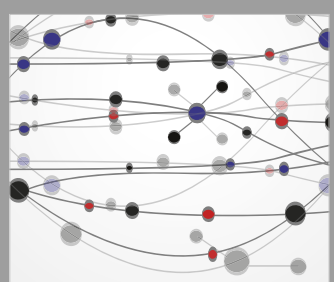

The Scientific World Journal
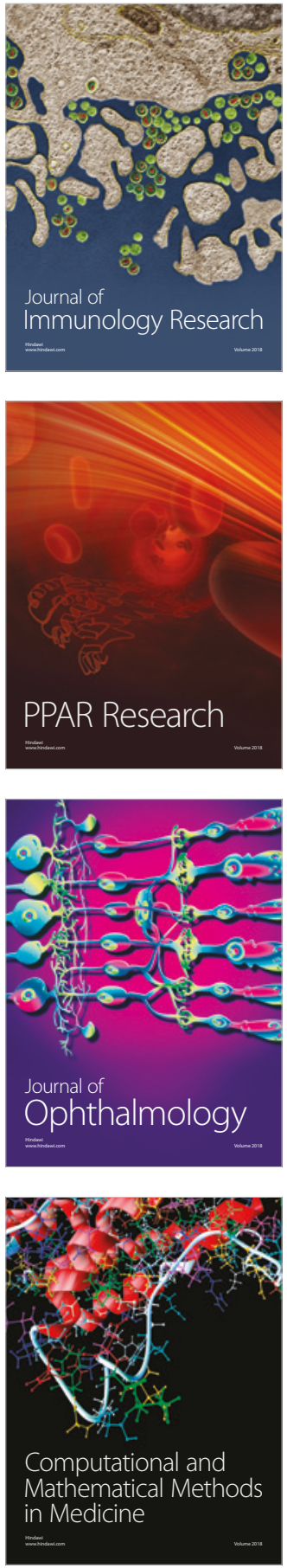

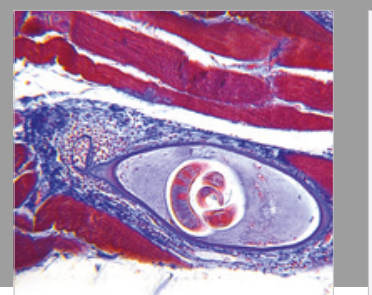

Gastroenterology Research and Practice

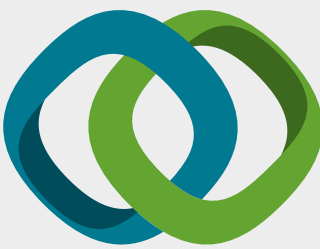

\section{Hindawi}

Submit your manuscripts at

www.hindawi.com
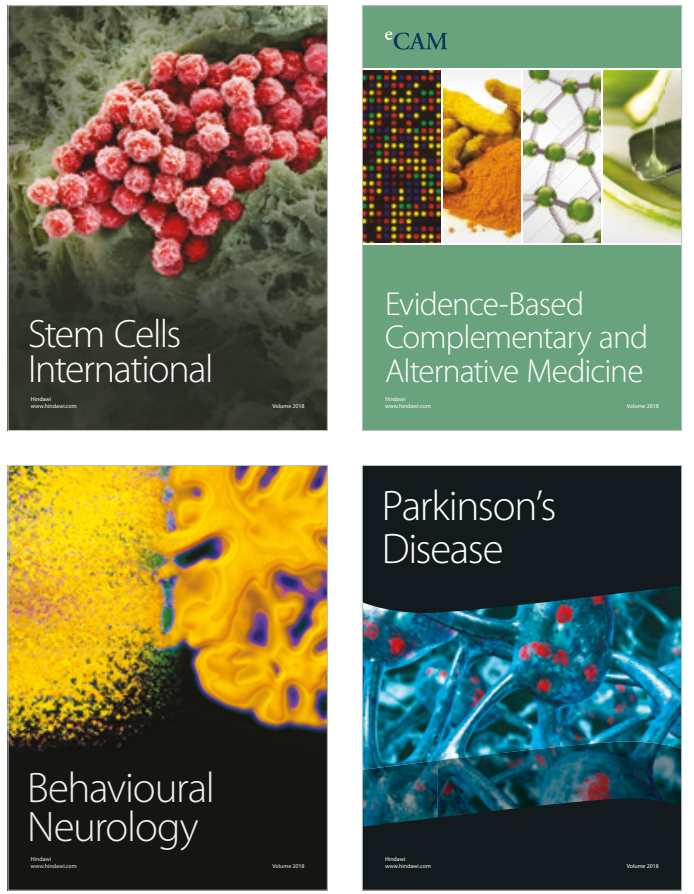

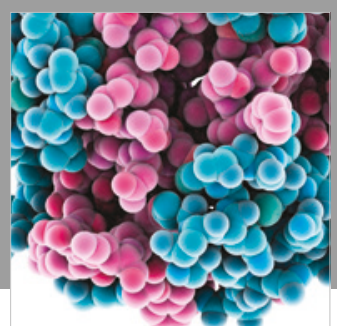

ournal of

Diabetes Research

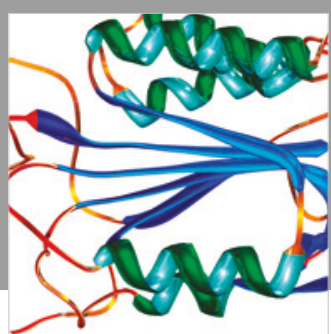

Disease Markers
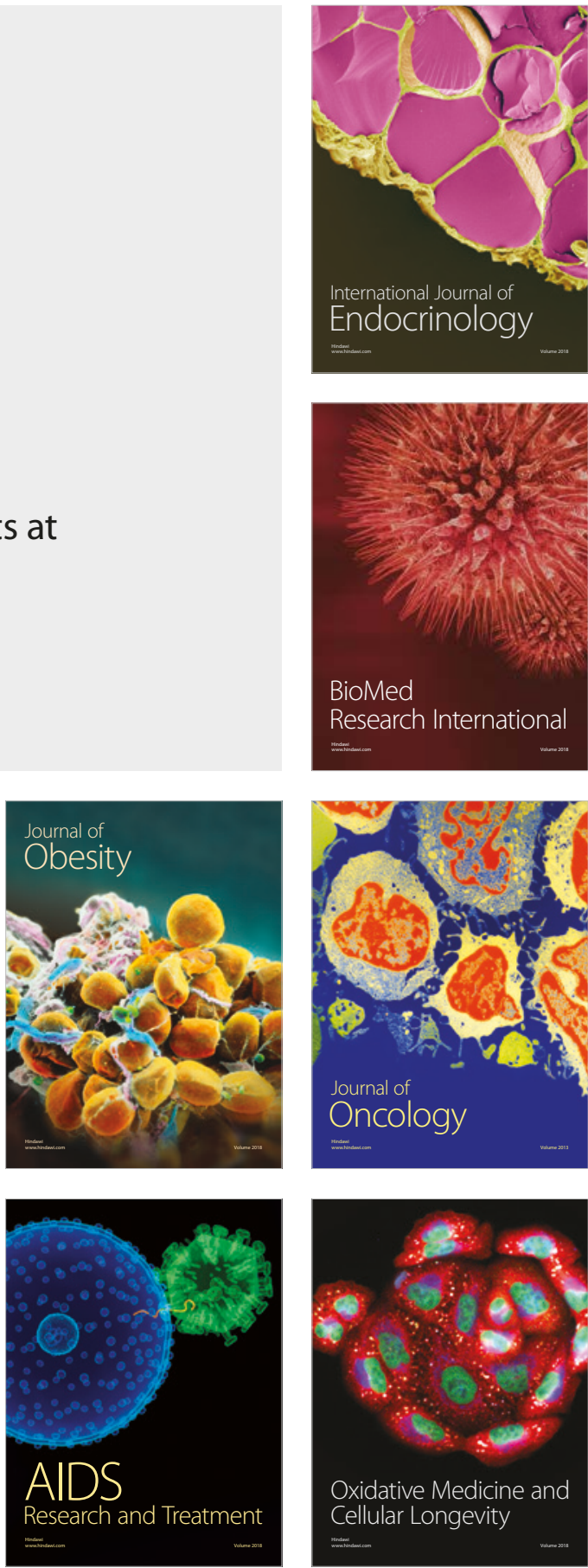